PIXEL, Vol.14, No.2 Desember 2021, pp. 242-252

p-ISSN : 1979-0414(print)

e-ISSN : 2621-6256 (online)

http://journal.stekom.ac.id/index.php/pixel

\title{
Desain Perancangan Sistem Pakar Diagnosa Penyakit Saluran Pernapasan Berbasis Web \\ Rayuwati Rayuwati
}

${ }^{1}$ Universitas Gajah Putih

Simpang Kelaping, Pegasing, Central Aceh Regency, Aceh 24552

\begin{tabular}{|c|c|}
\hline ARTICLE INFO & $A B S T R A C T$ \\
\hline $\begin{array}{l}\text { Article history: } \\
\text { Received } 30 \text { September } 2021 \\
\text { Received in revised form } 2 \text { Oktober } 2021 \\
\text { Accepted } 10 \text { Oktober } 2021 \\
\text { Available online Desember } 2021\end{array}$ & $\begin{array}{l}\text { Infeksi Saluran Pernapasan Akut } \\
\text { (ISPA) merupakan masalah kesehatan yang } \\
\text { sangat serius di Indonesia. Menurut Riset } \\
\text { Kesehatan Dasar (RISKESDAS) penyakit ISPA } \\
\text { tertinggi berada pada provinsi Nusa Tenggara } \\
\text { Timur (41,7\%), Papua }(31,1 \%) \text {, Aceh }(30,0 \%) \text {, } \\
\text { Nusa Tenggara Barat }(28,3 \%) \text {, dan Jawa Timur } \\
(28,3 \%) \text {. Pada Riskesdas } 2007 \text {, Nusa Tenggara } \\
\text { Timur juga merupakan provinsi tertinggi } \\
\text { dengan ISPA. Periode waktu penyebaran } \\
\text { penyakit ISPA di Indonesia menurut Riskesdas } \\
\text { tahun 2013 sebesar } 25,0 \% \text {, tidak jauh berbeda } \\
\text { dengan tahun 2007 sebesar } 25,5 \% \text {. } \\
\text { memeriksakan diri ke dokter dan cenderung } \\
\text { mengabaikan penyakit ini. Untuk solusi dari } \\
\text { permasalahan tersebut maka diperlukan suatu } \\
\text { sistem yang dapat membantu masyarakat dalam } \\
\text { mendiagnosa penyakit gangguan pernapasan } \\
\text { sehingga nantinya masyarakat dapat lebih } \\
\text { mudah berkonsultasi untuk mengantisipasi } \\
\text { dampak yang lebih buruk . Salah satu sistem } \\
\text { yang dapat digunakan untuk membantu } \\
\text { diagnosis adalah sistem pakar. Sistem ini bukan } \\
\text { untuk menggantikan kedudukan pakar, tetapi } \\
\text { memasyarakatkan pengetahuan dan pengalaman } \\
\text { seorang pakar. }\end{array}$ \\
\hline
\end{tabular}

Keywords: perancangan, pakar, Desain

\section{Pendahuluan}

Setiap orang pasti pernah terserang penyakit baik penyakit ringan maupun penyakit kronis. Berbagai faktor seperti musim, pola hidup yang tidak sehat serta tingkat kebersihan yang tergolong cukup rendah sering kali membuat berbagai macam organ yang ada di dalam tubuh manusia menjadi terserang penyakit. Penyakit yang sering muncul di masyarakat akibat faktor ini adalah penyakit gangguan pernapasan. Terganggunya sistem pernapasan maka manusia akan kesulitan untuk melakukan kegiatan atau pekerjaan. Penyakit yang terdapat pada sistem Received September 30, 2021; Revised Oktober 2, 2021; Accepted Oktober 10, 2021 
pernapasan manusia amatlah komplek. Anggapan bahwa penyakit yang diawali dengan gejala batuk atau flu biasa tidak akan membahayakan, tetapi orang awam tidak tahu apakah gejala awal tersebut merupakan gejala awal pada penyakit berat lainnya seperti TBC.

Infeksi Saluran Pernapasan Akut (ISPA) merupakan masalah kesehatan yang sangat serius di Indonesia. Menurut Riset Kesehatan Dasar (RISKESDAS) penyakit ISPA tertinggi berada pada provinsi Nusa Tenggara Timur (41,7\%), Papua (31,1\%), Aceh $(30,0 \%)$, Nusa Tenggara Barat (28,3\%), dan Jawa Timur (28,3\%). Pada Riskesdas 2007, Nusa Tenggara Timur juga merupakan provinsi tertinggi dengan ISPA. Periode waktu penyebaran penyakit ISPA di Indonesia menurut Riskesdas tahun 2013 sebesar 25,0\% , tidak jauh berbeda dengan tahun 2007 sebesar $25,5 \%$.

Masyarakat terkadang enggan untuk memeriksakan diri ke dokter dan cenderung mengabaikan penyakit ini. Beberapa hal yang menjadi alasan adalah biaya dan lamanya antrian. Bagi sebagian masyarakat, untuk periksa ke dokter membutuhkan biaya yang tidak sedikit belum lagi harus membeli obatnya selain itu juga harus menjalani antrian periksa yang tidak sebentar. Keterbatasan dokter dan tidak meratanya jumlah dokter makin memperburuk keadaan. Untuk solusi dari permasalahan tersebut maka diperlukan suatu sistem yang dapat membantu masyarakat dalam mendiagnosa penyakit gangguan pernapasan sehingga nantinya masyarakat dapat lebih mudah berkonsultasi untuk mengantisipasi dampak yang lebih buruk. Salah satu sistem yang dapat digunakan untuk membantu diagnosis adalah sistem pakar. Sistem ini bukan untuk menggantikan kedudukan pakar, tetapi memasyarakatkan pengetahuan dan pengalaman seorang pakar.

Sistem pakar ini dibangun dengan berbasis website untuk menyebarluaskan informasi kepada masyarakat sehingga upaya penanganan dan pencegahan sejak dini penyakit saluran pernapasan dapat dilakukan dengan cepat. Dari uraian yang disampaikan pada penelitian ini, maka penulis mengangkat tema tugas akhir tentang "Desain Perancangan Sistem Pakar Diagnosa Penyakit Saluran Pernapasan Berbasis Web".

\section{Tinjauan Pustaka}

Sistem Pakar (dalam bahasa Inggris :expert system) adalah sistem informasi yang berisi dengan pengetahuan dari pakar sehingga dapat digunakan untuk konsultasi. Pengetahuan dari pakar di dalam sistem ini digunakan sebagi dasar oleh Sistem Pakar untuk menjawab pertanyaan (konsultasi).

Kepakaran (expertise) adalah pengetahuan yang ekstensif dan spesifik yang diperoleh melalui rangkaian pelatihan, membaca, dan pengalaman. Pengetahuan membuat pakar dapat mengambil keputusan secara lebih baik dan lebih cepat daripada non-pakar dalam memecahkan problem yang kompleks. Kepakaran mempunyai sifat berjenjang, pakar top memiliki pengetahuan lebih banyak daripada pakar yunior. Tujuan Sistem Pakar adalah untuk mentransfer kepakaran dari seorang pakar ke komputer, kemudian ke orang lain (yang bukan pakar).

Sistem pakar adalah suatu program komputer yang mengandung pengetahuan dari satu atau lebih pakar manusia mengenai suatu bidang spesifik. Jenis program ini pertama kali dikembangkan oleh periset kecerdasan buatan pada dasawarsa 1960-an dan 1970-an dan diterapkan secara komersial selama 1980-an. Bentuk umum sistem pakar adalah suatu program yang dibuat berdasarkan suatu set aturan yang menganalisis informasi (biasanya diberikan oleh pengguna suatu sistem) mengenai suatu kelas masalah spesifik serta analisis matematis dari masalah tersebut. Tergantung dari desainnya, sistem pakar juga mampu merekomendasikan suatu rangkaian tindakan pengguna untuk dapat menerapkan koreksi. Sistem ini memanfaatkan kapabilitas penalaran untuk mencapai suatu simpulan.

Sistem pakar disusun oleh dua bagian utama, yaitu lingkungan pengembangan (development environment) dan lingkungan konsultasi (consulation environment). Lingkungan pengembangan sistem pakar digunakan untuk memasukkan pengetahuan pakar ke dalam 
lingkungan sistem pakar, sedangkan lingkungan konsultasi digunakan pengguna yang bukan pakar guna memperoleh pengetahuan pakar.[1]

Sistem pernapasan (sistem respirasi) merupakan sistem organ yang dipakai sebagai pertukaran gas. Sistem pernapasan pada umumnya termasuk saluran yang dipakai untuk membawa udara masuk ke dalam paru-paru, di mana disana terjadi pertukaran gas. Diafragma menarik udara masuk dan juga mengeluarkannya. Berbagai variasi sistem pernapasan ditemukan pada berbagai jenis makhluk hidup. Bahkan pohon pun memiliki sistem pernapasan. Organ-organ pernapasan meliputi hidung, faring, laring, trakea, bronkus, paru-paru, alveolus. [2]

Sejumlah teori telah ditemukan untuk menyelesaikan ketidakpastian, termasuk diantaranya probabilitas klasik, probabilitas bayes, teori hartley berdasarkan himpunan klasik, teori shannon berdasakan pada probabilitas, teori Depmster-Shafer, teori fuzzy Zadeh, dan faktor kepastian (certanity factor). Faktor kepastian (Certanity Factor) diperkenalkan oleh Shortliffe Buchanan dalam pembuatan MYCIN. Certanity Factor (CF) merupakan nilai parameter klinis yang diberikan MYCIN untuk menunjukkan besarnya kepercayaan.

Faktor kepastian (certainty factor) menunjukkan ukuran kepastian terhadap suatu fakta atau aturan. Metode certainty factor ini hanya bisa mengolah 2 bobot dalam sekali perhitungan. Untuk bobot yang lebih dari 2 banyaknya, untuk melakukan perhitungan tidak terjadi masalah apabila bobot yang dihitung teracak, artinya tidak ada aturan untuk mengkombinasikan bobotnya, karena untuk kombinasi seperti apapun hasilnya akan tetap sama. Misalnya untuk mengetahui apakah seorang pasien tersebut menderita suatu penyakit atau tidak, itu dilihat dari hasil perhitungan bobot setelah semua keluhan-keluhan diinputkan dan semua bobot dihitung dengan menggunakan metode certainty factors. [4]

\section{Metode R\&D}

Menurut (Prasetyo 2014) Research and Development adalah metode penelitian yang digunakan untuk menghasilkan produk tertentu dan menguji keefektifan produk tersebut.[13] Perlu dipahami pula bahwa R\&D merupakan metode penelitian multi tahap bahkan dalam beberapa kasus, penelitian dengan metode ini memakan waktu lebih dari satu tahun, sehingga peneliti perlu untuk lebih terampil dalam merencanakan penelitian ini agar hasil yang diharapkan dapat diperoleh sesuai dengan waktu yang direncanakan. Sesuai dengan namanya, Research \& Developmnet difahami sebagai kegiatan penelitian yang dimulai dengan research dan diteruskan dengan development. Kegiatan research dilakukan untuk mendapatkan informasi tentang kebutuhan pengguna (needs assessment) sedangkan kegiatan development dilakukan untuk menghasilkan perangkat pembelajaran.

Desain arsitektur aplikasi sistem pakar ini terdiri dari dua pengguna, yaitu user expert dan user umum. Desain arsitektur dari sisi user expert tidak dapat dipisahkan dari sisi user umum, karena semua elemen-elemen yang ada saling berhubungan. Desain arsitektur aplikasi sistem pakar ini dapat dilihat pada Gambar 3.1 berikut.

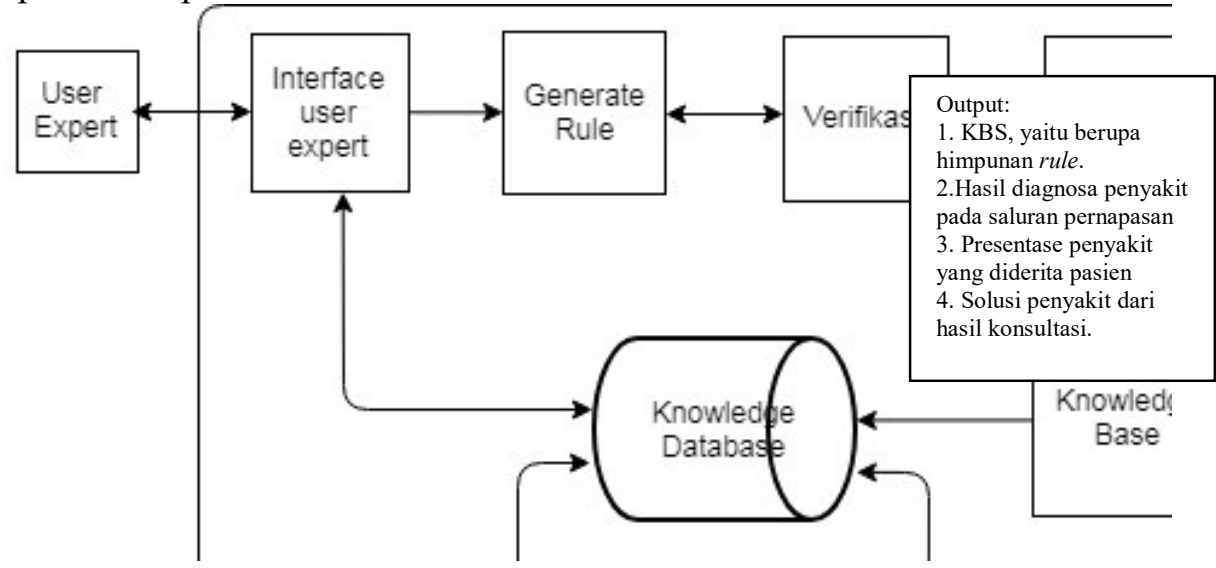

Gambar 3.1 Desain Arsitektur Penyakit Saluran Pernapasan

JURNAL ILMIAH KOMPUTER GRAFIS Vol. 14, No. 1, Desember $2021: 242-252$ 
Penjelasan dari Gambar diatas adalah sebagai berikut:

1. Interface user expert: suatu media yang digunakan oleh user expert (pakar) untuk memasukkan parameter rules. Parameter yang dimasukan adalah tentang jenis penyakit, gejala-gejala penyakit dan solusi penyakit saluran pernapasan untuk menghasilkan basis pengetahuan (knowledge base System).

2. Generate rule: proses ini dilakukan untuk membangkitan rules.

3. Verifikasi: yaitu melakukan proses verifikasi pada rules yang dibangun dan dimasukan ke dalam sistem dengan tujuan untuk mendapatkan rules yang benar sesuai dengan teori verifikasi.

4. Reduced Rule: rules yang telah diverifikasi.

5. Knowledge base: merupakan kumpulan pengetahuan dan rules yang diperoleh sistem selama proses berlangsung.

6. Knowledge database: digunakan untuk mengembangkan knowledge base apabila ada perubahan pada rules yang ada.

7. Interface user umum: digunakan oleh user umum untuk berinteraksi dengan sistem, dengan memlakukan konsultasi untuk mendapatkan hasil dari diagnosa.

8. Inference engine: mekanisme inferensi yang digunakan adalah metode Faktor kepastian (Certainty Factor). Metode ini akan memproses setiap masukan dari user umum untuk mendapatkan suatu diagnosis penyakit saluran pernapasan dan memberikan solusi dalam pengendaliannya sesuai dengan knowledge base yang telah dibuat oleh user expert.

9. Output: hasil yang didapat dari sistem yang dapat menunjukan jawaban dari konsultasi yang telah dilakukan oleh user.

\section{Data Flow Diagram Level 0}

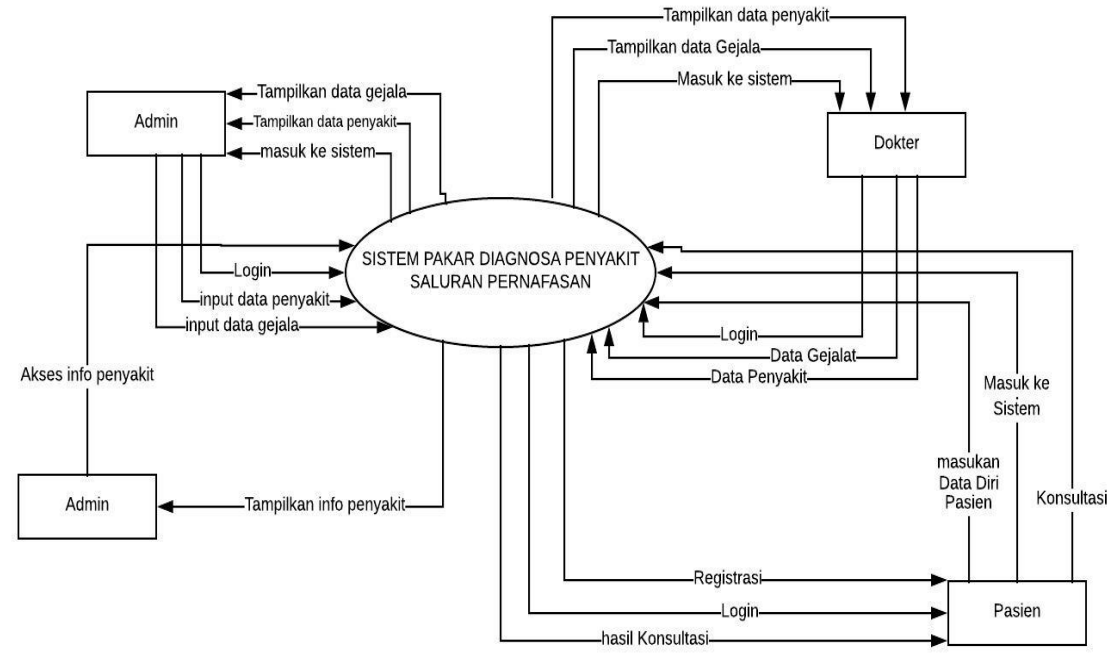

Gambar 3.2 Data Flow Diagram Level 0 


\section{Data Flow Diagram Level 1}

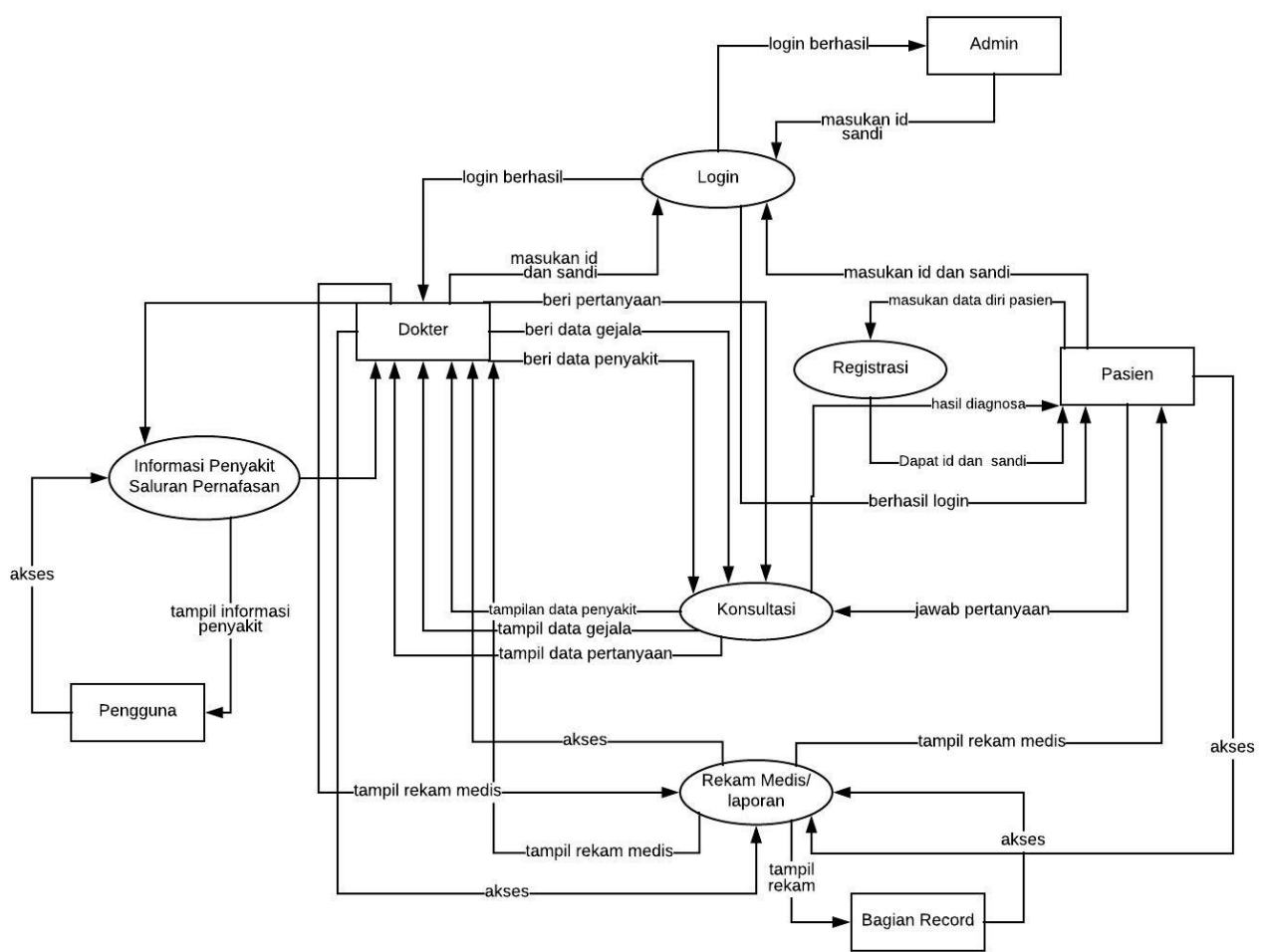

Gambar 3.3 Data Flow Diagram Level 1

\section{Usecase Diagram}

Perancangan sistem pakar diagnosa penyakit Saluran Pernapasan yang dikembangkan menggunakan diagram unified modeling language (UML), diagram yang digunakan yaitu usecase diagram. Usecase diagram merupakan suatu langkah penting yang harus dilakukan dalam menyelesaikan suatu masalah. Berisi alur untuk membantu bagaimana suatu sistem dapat berjalan. 


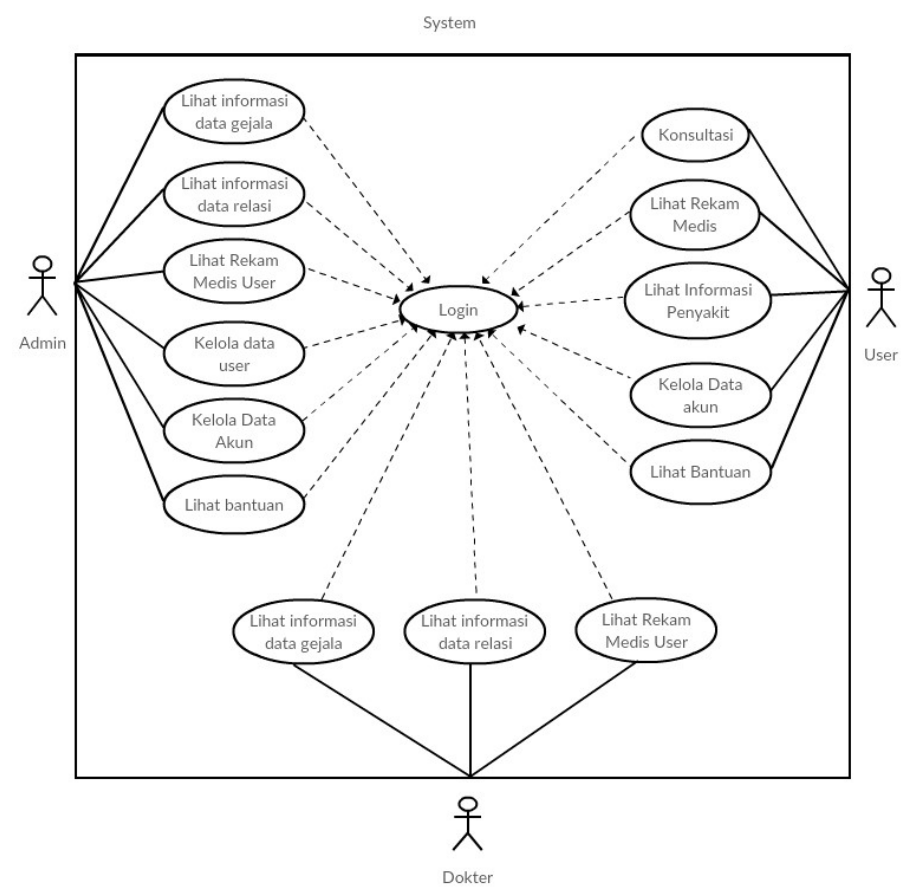

Gambar 3.5 Use Case Diagram

\section{Activity Diagram}

Activity diagram untuk Sistem Pakar Diagnosa Penyakit Saluran Pernapasan digambarkan dalam enam kategori yaitu:

1. Activity Diagram dari Use Case Login

Activity Diagram dari use case login ini digunakan bagi admin dan dokter atau pakar yang telah terdaftar sebagai admin dan pakar yang mempunyai username dan password, dapat melakukan login ke halaman admin/pakar. Apabila username dan password yang dimasukkan tervalidasi pada basisdata maka sistem akan menampilkan halaman utama untuk admin/par. Gambar activity diagram login dapat dilihat pada gambar 3.6 berikut ini:

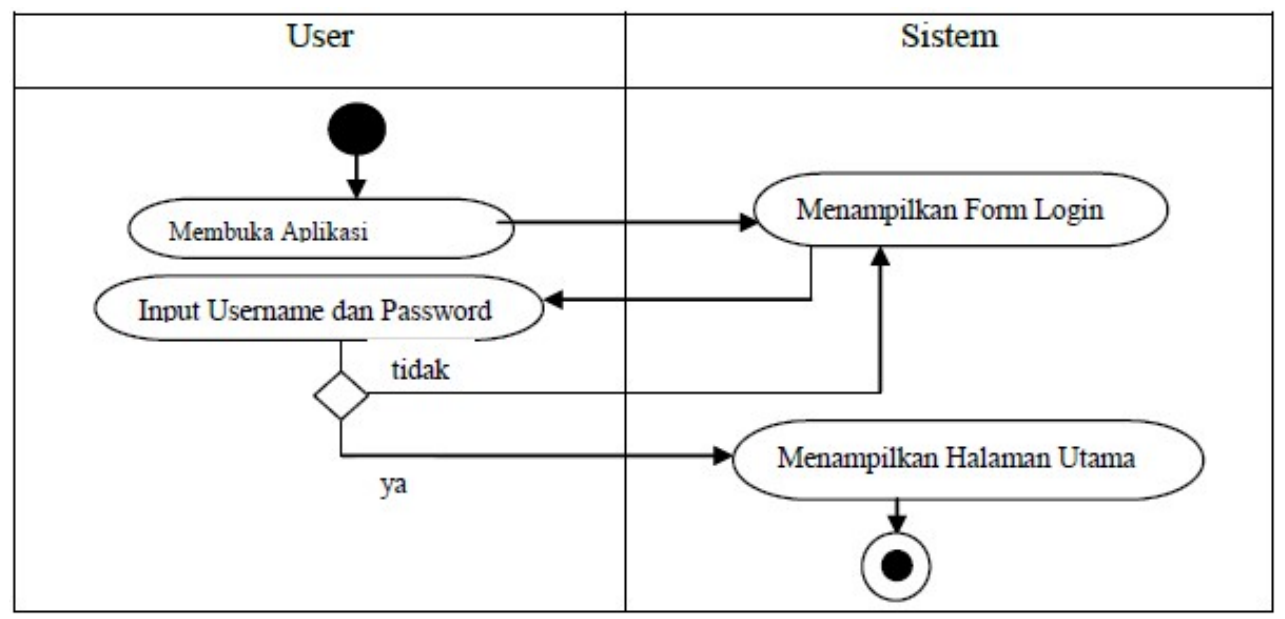

Gambar 3.6 Activity Diagram dari Use Case Login Admin/Pakar 
2. Activity Diagram Manajemen Gejala Oleh Admin

Aktifitas dalam manajemen Gejala dimulai pada saat admin login untuk manambah dan mengedit Data Gejala dengan memasukkan kdgejala dan nmgejala. Mengenai alur activity diagram sistem pada manajemen gejala dapat dilihat pada gambar 3.7 berikut ini:

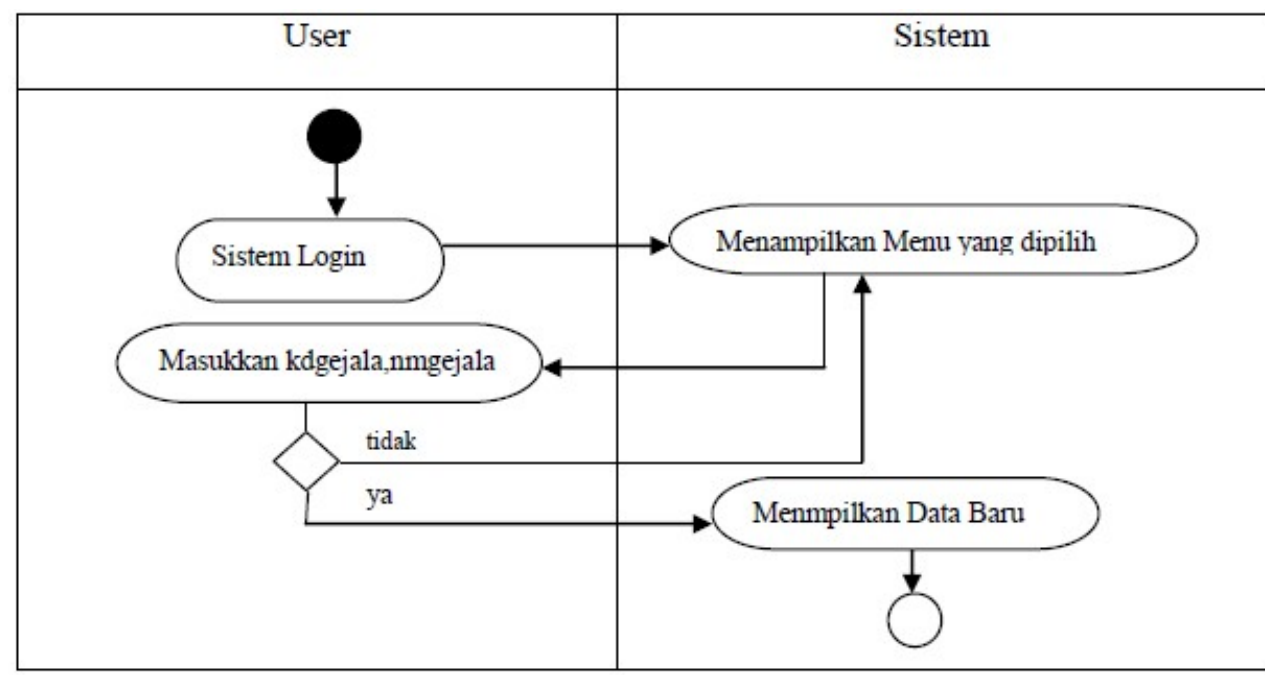

Gambar 3.7 Activity Diagram dari Use Case Manajemen Gejala

3. Activity Diagram Manajemen Penyakit Oleh Admin

Aktifitas dalam manajemen Penyakit dimulai pada saat admin login untuk manambah dan mengedit Data Penyakit dengan memasukkan kdpenyakit dan nmpenyakit. Activity diagramnya dapat dilihat pada gambar 3.8 berikut ini:

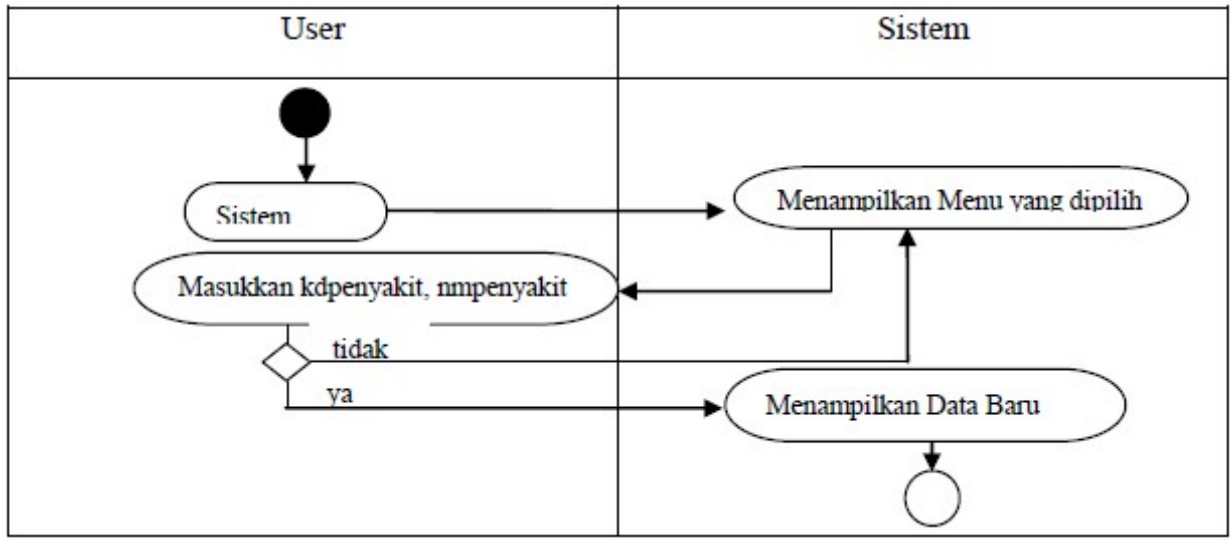

Gambar 3.8 Activity Diagram dari Use Case Manajemen Penyakit

4. Activity Diagram Manajemen Role Oleh Admin

Aktifitas dalam manajemen Role dimulai pada saat admin login untuk manambah dan mengedit data penyakit dengan memasukkan kdpenyakit,kdgejala dan nilaimb. Mengenai alur activity diagram sistem pada manajemen Role dapat dilihat pada gambar 3.9 berikut ini:

JURNAL ILMIAH KOMPUTER GRAFIS Vol. 14, No. 1, Desember $2021: 242-252$ 


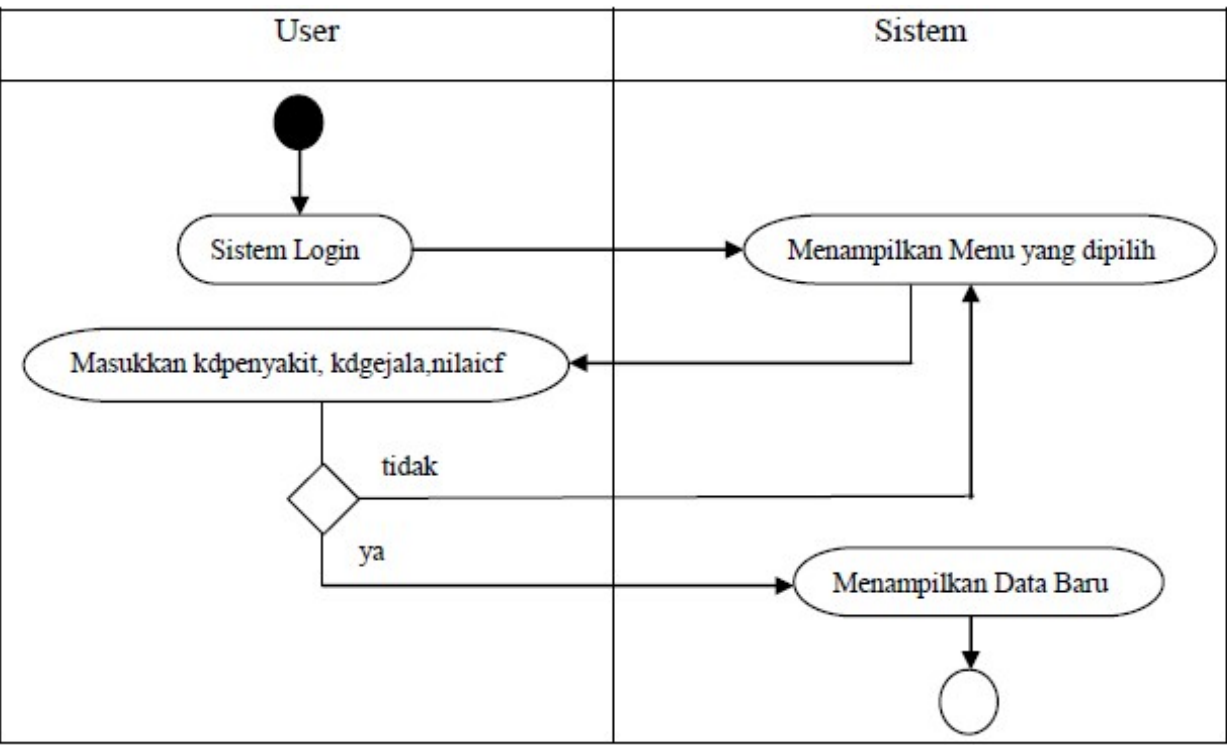

Gambar 3.9 Activity Diagram dari Use Case Manajemen Rule

\section{Hasil dan Pembahasan}

Halaman menu utama adalah merupakan halaman awal ketika website dijalankan. Pada halaman ini, terlihat bahwa menu yang dapat diakses adalah beranda dan masuk atau login.

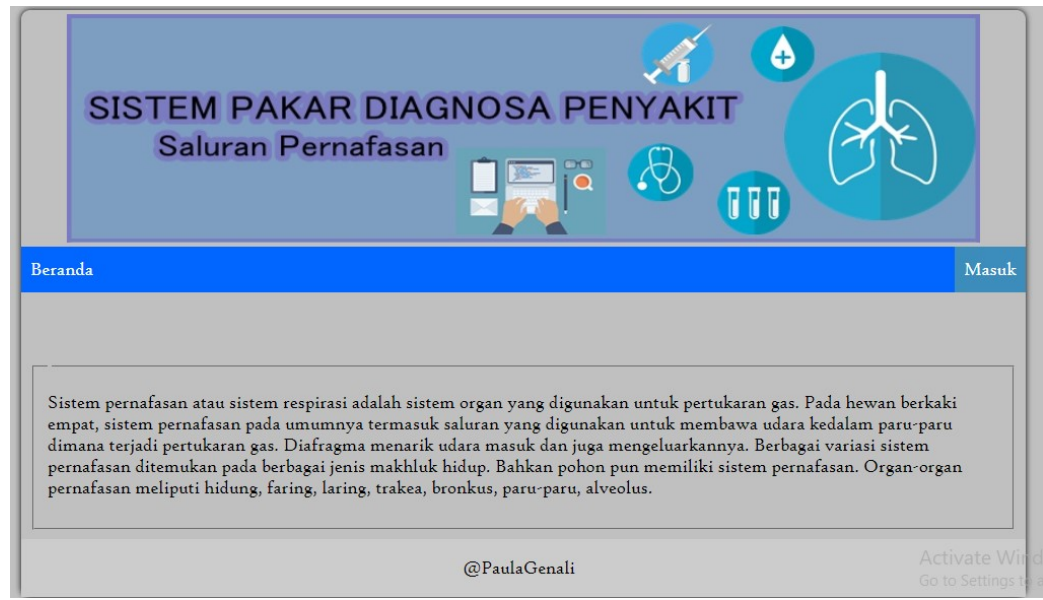

Gambar 4.1 Tampilan halaman utama

1. Halaman Menu Login

Halaman login ini digunakan oleh pakar, admin, dan pasien ketika ingin masuk dan menggunakan sistem dengan cara memasukan username, password dan memilih level. 
SILAHKAN LOGIN

Username

Username.

Password

Password

Pilih Level

LOGIN Daftar Lupa Pass

Gambar 4.2 Halaman menu login

2. Halaman Menu Daftar User

Halaman ini digunakan oleh user untuk melakukan registrasi agar dapat masuk ke sistem dan melakukan diagnosa penyakit.

\begin{tabular}{|l|}
\hline Nama \\
\hline Nama ... \\
\hline Username \\
\hline Username ... \\
\hline Password \\
\hline Password ... \\
\hline No Reg \\
\hline Reg-005 \\
\hline Email \\
\hline Email... \\
\hline simpan \\
\hline
\end{tabular}

Gambar 4.3 Halaman menu daftar user

3. Halaman Lupa Password

Jika user lupa password maka dapat pergi ke menu lupa password dengan syarat user harus mengingat nomor registrasi yang telah diberikan ketika mendaftar.

LUPA PASSWORD

User Name

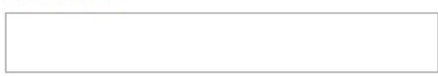

No Reg

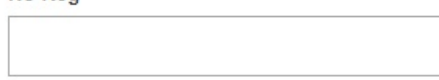

Pass Baru

JURNAL ILMIAH KOMPUTER GRAFIS Vol. 14, No. 1, Desember $2021: 242-252$ 
Gambar 4.4 Halaman lupa password

4. Halaman Menu Admin

Halaman menu admin ini digunakan oleh admin untuk mengelola sistem serta dapat melakukan penginputan data dan lihat data user atau pasien yang telah melakukan registrasi serta admin juga dapat melihat rekam medis pasien yang telah melakukan diagnosa.

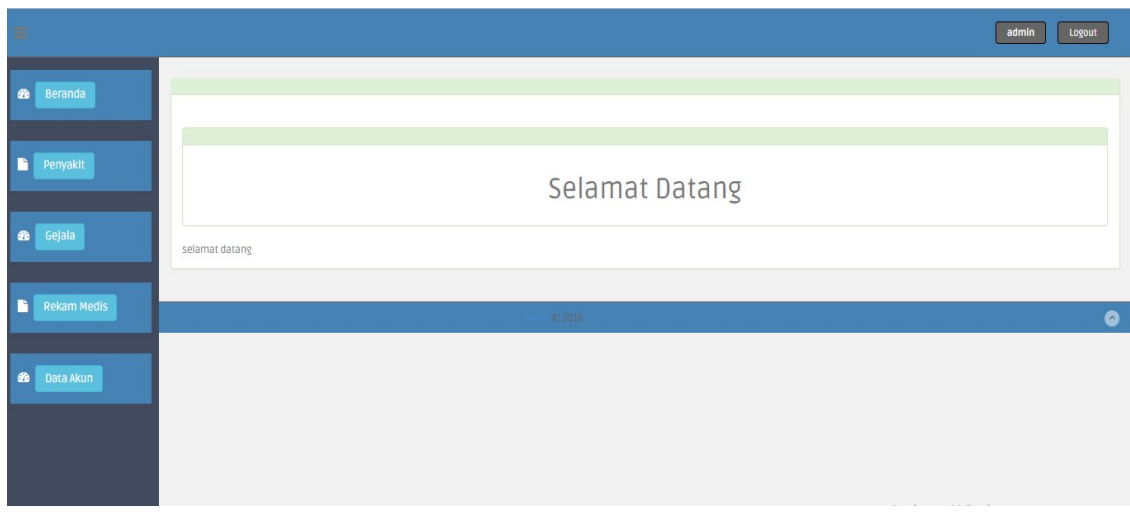

5. Halaman Penyakit

Gambar 4.5 Halaman Menu Admin

Halaman ini digunakan oleh admin dan dokter untuk melihat, menginputkan, mengubah, dan menghapus data penyakit.

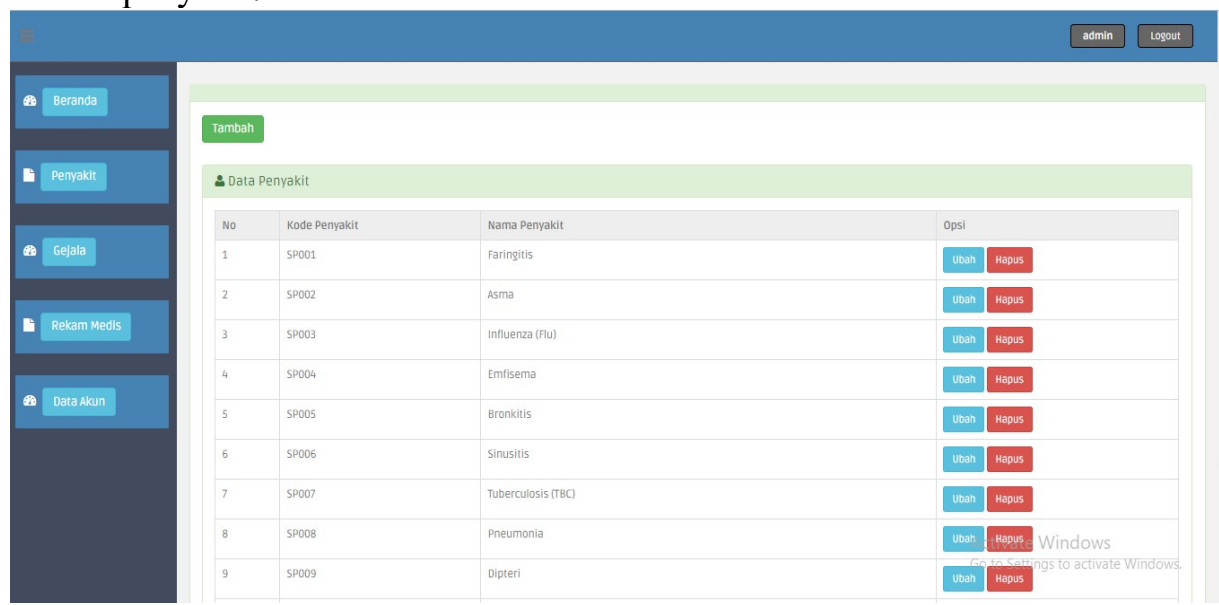

Gambar 4.6 Halaman Penyakit

6. Halaman Tambah Penyakit

Halaman ini digunakan oleh admin untuk menambah data penyakit dengan cara memasukan kode penyakit serta nama penyakit. 


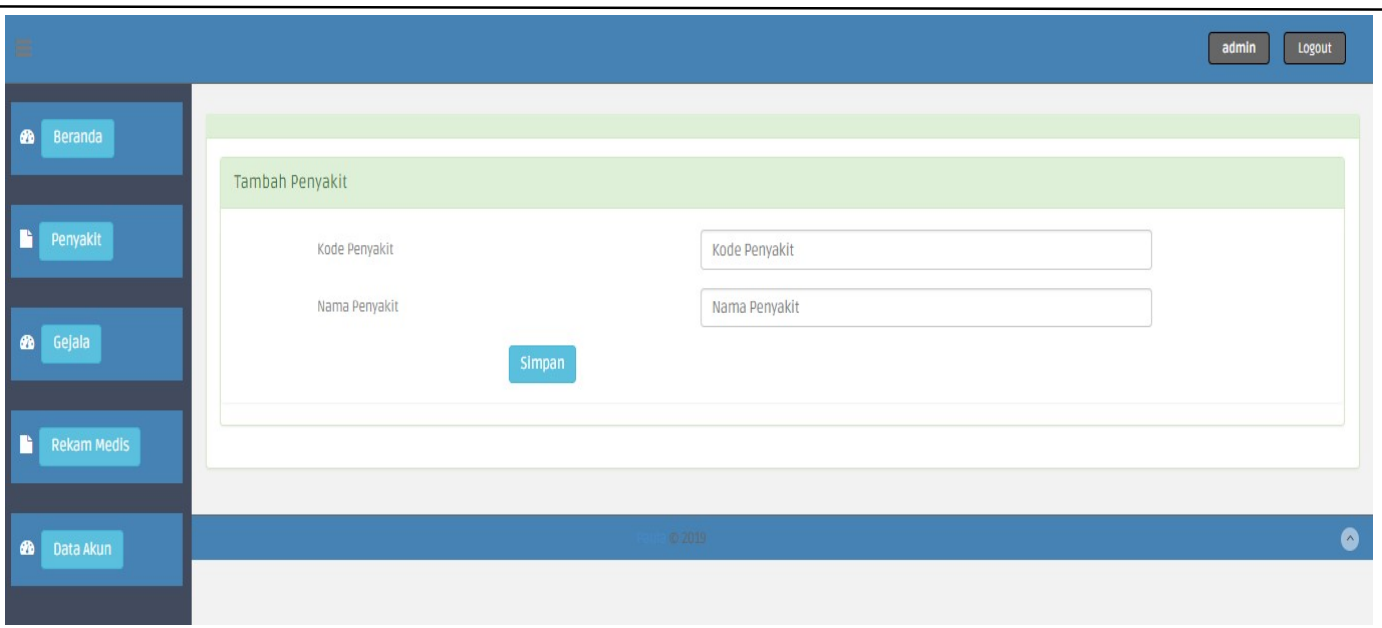

Gambar 4.7 Halaman tambah Penyakit

7. Halaman Ubah Penyakit

Halaman ini digunakan oleh admin untuk mengubah data penyakit dengan cara mengubah kode dan nama penyakit.

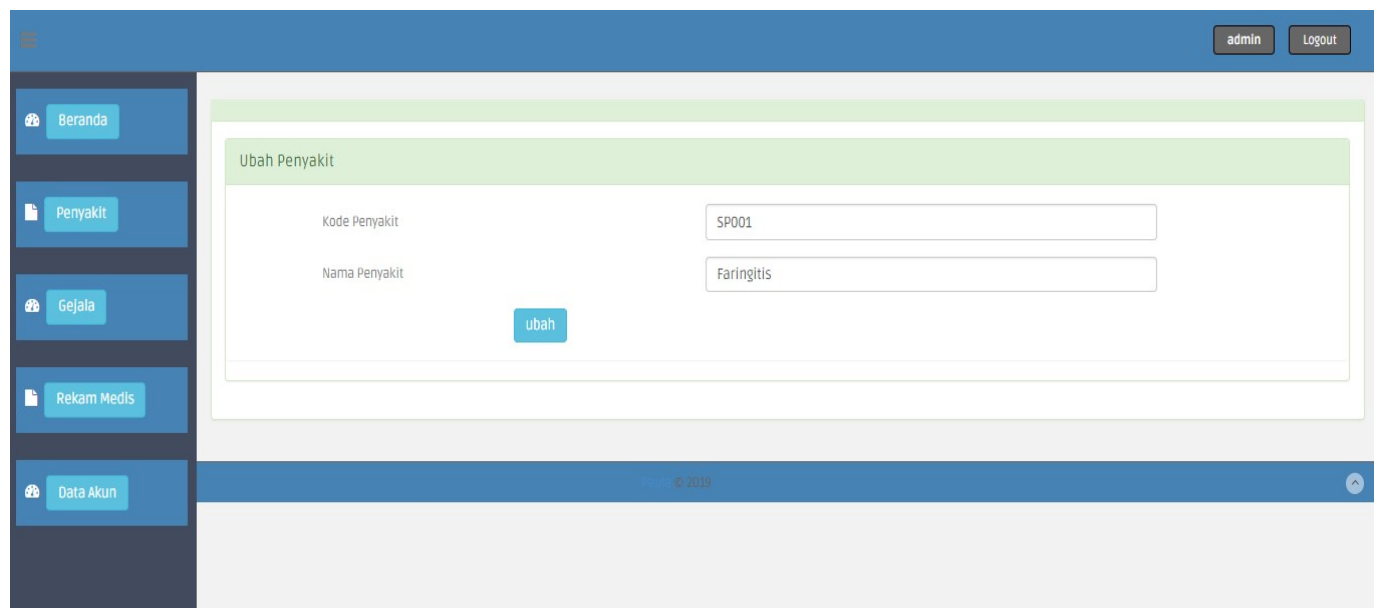

Gambar 4.8 Halaman Ubah Penyakit

8. Halaman tambah Gejala

Halaman ini digunakan oleh admin untuk tambah data gejala dimana admin menginputkan kode gejala, nama gejalan serta nilai mb atau bobot gejala yang telah diberikan oleh pakar. 


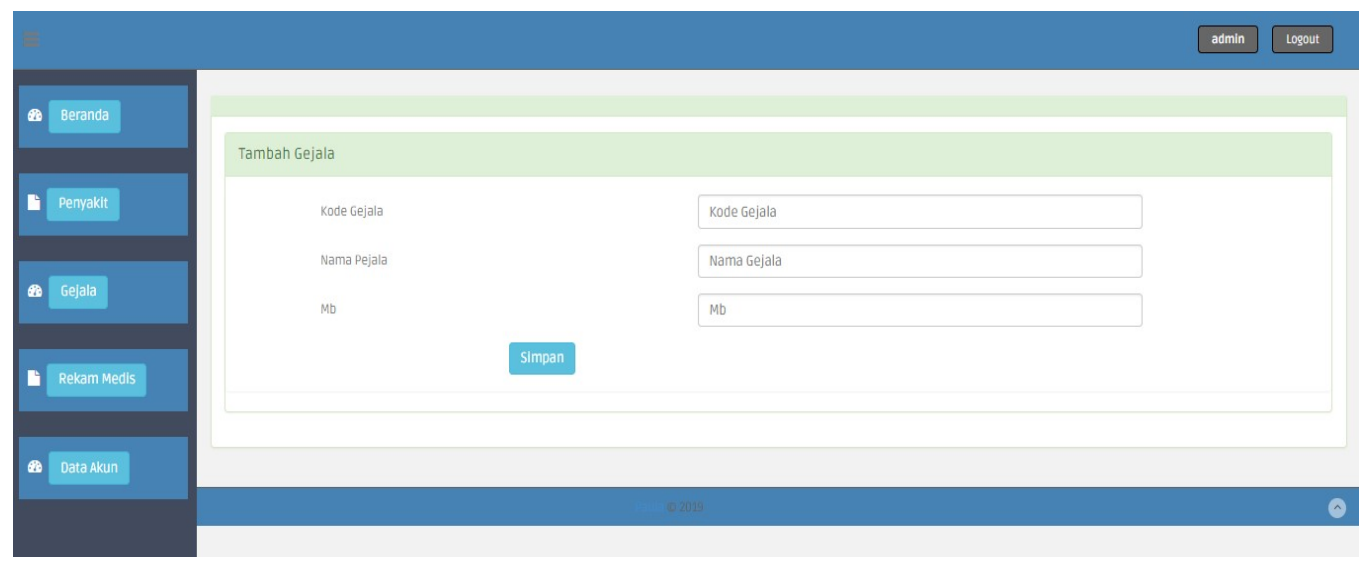

Gambar 4.9 Halaman tambah Gejala

\section{Kesimpulan dan Saran}

Adapun hasil pada penelitian ini adalah sebagai berikut :

1. Pengembangan aplikasi sistem pakar ini ditujukan untuk mensubstitusikan pengetahuan dari seorang pakar ke dalam bentuk suatu sistem, sehingga dapat digunakan oleh masyarakat secara bebas.

2. Sistem dapat mendeteksi penyakit yang diderita oleh user dengan melakukan perhitungan berdasarkan nilai aturan/rule yang diberikan oleh pakar dan nilai kepercayaan berdasarkan tingkat kepercayaan gejala yang dimiliki oleh user.

3. Penerapan metode Certainty factor dapat mempermudah dan memberikan perhitungan penyelesaian seberapa pasti user atau pasien menderita penyakit saluran pernapasan.

4. Sistem dibangun berbasis web sehingga masyarakat dapat mendiagnosa kemungkinan penyakit saluran pernapasan yang diderita sebelum mengambil tindakan lebih lanjut seperti konsultasi ke dokter atau rumah sakit.

5. Dengan perhitungan pada Sistem Pakar Diagnosa Penyakit Saluran Pernapasan Menggunakan Metode Certainty Factor di dapat nilai kepercayaan dari hasil diagnosa dengan nilai tingkat akurasi $75 \%$.

Adapun saran dari penelitian sistem pakar diagnosa penyakit saluran pernapasan ini masih banyak kekurangan di antaranya :

1. Diharapkan kedepannya terdapat pengembangan-pengembangan yang lebih baik pada isi, tampilan serta akses terhadap aplikasi dan penulis berharap sistem pakar ini dapat dikembangkan ke perangkat mobile.

2. Penambahan data penyakit pada diagnosa penyakit Saluran Pernapasan.

3. Gejala-gejala pada sistem pakar untuk mendiagnosa penyakit Saluran Pernapasan dapat ditambahkan dengan hasil pemeriksaan laboratorium agar hasil diagnosa dapat lebih akurat.

\section{DAFTAR PUSTAKA}

Agustona, Dkk, 2015. "Sistem Pakar Diagnosa Penyakit Kulit Akibat Infeksi Jamur"

Arhami, Muhammad, 2004 “Konsep Dasar Sistem Pakar” Jilid 1,Yogyakarta

Ashari, \& Muniar, Yuliar, 2016. "Penerapan Sistem Pakar Untuk Mendiagnosa Penyakit Pencernaan Dengan Pengobatan Bahan Alami” 
Iskandar, Kusrini, 2009 "Metode Kuantifikasi untuk Mendapatkan Nilai Certainty Factor Pengguna"

Kurniawan, Aris, "Pengertian Sistem Pernapasan Pada Manusia Lengkap" http://www.gurupendidikan.com/pengertian-sistem-pernafasan-pada-manusia-lengkap/ (diakses pada 28 November 2018)

Mayasari, Dian, "Kelainan atau Penyakit Pada Pernapasan Manusia" https://doktersehat.com/kelainan-atau-penyakit-pada-pernapasan-manusia/ (diakses pada tanggal 30 November 2018)

Ongko, Erianto, 2013. "Perancangan Sistem Pakar Diagnosa Penyakit pada Mata"

Panduan, Anhar, 2010. "Menguasai PHP\&MySQL secara otodidak"

Supyani, Dkk, 2015. “Aplikasi Diagnosa Kerusakan Mesin Sepeda Motor Bebek 4 Tak Dengan Metode Forward Chaining"

Triyanto, Sulis, \& Fadlil, Abdul, 2014. "Sistem Pakar Untuk Mendiagnosa Penyakit Kelinci Berbasis Web"

Wikipedia, "Diagram alir data" https://id.wikipedia.org/wiki/Diagram alir data (diakses pada tanggal 30 November 2018) 